\title{
A AFETIVIDADE E O PROCESSO ENSINO-APRENDIZAGEM: UM ESTUDO SOBRE A RELAÇÃO PROFESSOR-ALUNO NOS ANOS INICIAIS DO ENSINO FUNDAMENTAL.
}

\author{
AUTORES \\ Rosiane Maria Pantoja de Sousa \\ CPF: 598.042.112.20 \\ TANIA LUCIA DE SOUZA PAES \\ CPF:756.289.882.00 \\ JOSIELI FERREIRA GAIA \\ CPF: 948.243.202.91
}

\begin{abstract}
RESUMO
O presente artigo versa sobre a importância pedagógica da afetividade no processo ensino e aprendizagem escolar nos anos iniciais do ensino fundamental. Objetivamos com este artigo: Discutir a importância do trabalho pedagógico escolar nos anos iniciais do ensino fundamental com base na teoria da afetividade. Para alcançar o objetivo proposto demandou uma reflexão profunda sobre como a afetividade interferem positiva ou negativamente no processo ensino-aprendizagem escolar. Por essa razão trabalhamos com a metodologia de pesquisa bibliográfica que buscou nas teorizações de Vygotsky e Wallon, o embasamento necessário para compreender as contribuições da teoria da afetividade no desenvolvimento escolar e social dos alunos. Nesse sentido, constatamos que a afetividade ocupa papel central no desenvolvimento humano e que sua negligência no trabalho pedagógico escolar implica em sérios prejuízos ao processo de aprendizagem dos alunos. E importante ainda destacar que o professor tem um papel de grande relevância no trabalho com a afetividade na sala de aula e pode a partir de sua prática contribuir para 0 desenvolvimento positivo dos alunos ou não.
\end{abstract}

Palavras-Chave: Afetividade. Ensino-Aprendizagem. Desenvolvimento.

\section{1 - INTRODUÇÃO}

As transformações vivenciadas na sociedade têm implicado na prática escolar, alterando significativamente a forma de se conceber o processo ensinoaprendizagem, bem como, a finalidade da formação que é oferecida aos sujeitos. Diante de uma sociedade carente em muitos sentidos, como financeiro e o afetivo, a escola passa a tomar para si a responsabilidade de prover os alunos não apenas de conhecimento científico, mas de afeto, de perspectiva de futuro, de transformação social, dentre outras em que haja necessidade. 
Portanto, pode-se dizer que os alunos não procuram a escola apenas para ter acesso ao conhecimento científico. Muitas vezes, procuram a escola como uma espécie de refúgio, já que é comum a existência de problemas e conflitos em seus ambientes familiares. Sendo assim, o professor além de prover seus alunos de conhecimento deve estar atento para que não torne o momento de sala de aula outro tormento para este aluno, a ponto de este ir em busca de outros espaços para sanar suas carências, e venha a fracassar na escola.

Nesse sentido, para o desenvolvimento deste artigo trabalhamos com o seguinte objetivo geral: Discutir a importância do trabalho pedagógico escolar nos anos iniciais do ensino fundamental com base na teoria da afetividade; e como objetivos específicos: Conhecer as teorias da afetividade e como as mesmas podem ser aplicadas as práticas pedagógicas escolares; Identificar como a afetividade auxilia o processo ensino-aprendizagem escolar; Saber como as teorias da afetividade contribuem no desenvolvimento escolar e social dos alunos dos anos iniciais do ensino fundamental.

Como metodologia trabalhamos com a pesquisa bibliográfica, no qual fizemos a seleção dos referenciais teóricos a partir dos debates em torno da teoria da afetividade aplicada ao desenvolvimento humano a partir de Vygotsky e Wallon. Vale ressaltar que as reflexões apresentadas são resultado de nossa experiência como professora dos anos iniciais do ensino fundamental e das contribuições oferecidas pelos referenciais teóricos. Constatamos com este artigo que o trabalho docente para que cumpra seu papel na formação dos sujeitos deve levar em consideração as relações afetivas que transitam pela sala de aula/escola e que em muitos aspectos interferem ou contribuem para aprendizagem e desenvolvimento saudável dos alunos.

\section{Afetividade, situações de aprendizagem e desenvolvimento humano.}

Tem sido constante e cada vez mais crescentes os debates em torno do desenvolvimento das potencialidades humanas. Áreas distintas têm buscado compreender como tal processo acontece e em decorrência de que fatores. É fato que o desenvolvimento humano em sua totalidade deriva/necessita de inúmeros fatores, dentre os quais, se pode citar a afetividade. Nesse sentido, Antunes (2006, p. 05) assegura que: 
A afetividade se encontra "escrita" na história genética da pessoa humana e deve-se a evolução biológica da espécie. Como o ser humano nasce extremamente imaturo, sua sobrevivência requer a necessidade do outro, e essa necessidade se traduz em amor.

No entendimento do autor, que segue os pressupostos básicos da teoria vygotskiana, a afetividade eleva o indivíduo a diferentes patamares, assim como permite que os sujeitos por meio dela manifestem seus sentimentos, sensações e reações diante das pessoas animais e objetos. Assim, o processo de aprendizagem humana se consolida a partir do momento em que, o ser passa por transformações comportamentais resultantes das experiências que vai construindo. Nesse sentido, podemos inferir que a afetividade é também uma forma de aprendizagem, à medida que permite aos seres humanos se adaptarem ao ambiente em que estão colocados. É importante que se diga que a afetividade possuí duas dimensões que são; a do afeto e também a do desafeto, ou ainda, dentro da afetividade coexistem sentimentos "bons", como o amor e alegria, e "ruins", como o ódio, a tristeza e a dor.

Sobre o lado negativo da afetividade, Maldonado (1994) se lança ao desafio de compreender como o medo como sentimento presente nas relações afetivas e nas práticas de ensino e aprendizagem acaba por muitas vezes dificultar o relacionamento entre as pessoas. Nesse sentido, a autora problematizou, os chamados "desafetos", em especial o medo, para orientar os professores a como agir no espaço da sala de aula, pois o medo decorrente de uma postura drástica e centralizadora pode criar e desenvolver sérios traumas nos alunos. Sendo assim,

\footnotetext{
Atitudes ríspidas, grosseiras e agressivas expressam, com frequência, a necessidade de formar uma carapuça protetora contra o medo de ser rejeitado, contra sentimentos de inadequação ("já que sou mesmo incompetente para tantas coisas, por aí eu me destaco") e contra a dor do desamor ("ninguém gosta de mim mesmo, quero mais é explodir o mundo"). (MALDONADO, 1994, p.39).
}

A necessidade do amor faz com que, as pessoas criem para si uma espécie de proteção, especialmente quando sentem que podem ser rejeitadas. Nesse aspecto, o professor deve estar atento às diferentes manifestações da afetividade em sala de aula, para poder trabalhar as mesmas. Sobre a necessidade de se proteger dos alunos, adotando posturas e posições mais ríspidas, no entendimento do autor, isso é uma espécie de pedido de socorro, que o professor necessita estar atento para poder trabalhar os sentimentos e as emoções desses alunos.

Comportamentos inadequados, assim como manifestação de sentimentos negativos no que diz respeito à afetividade, são na maioria das vezes, problemas 
relacionados à autoestima, mais precisamente da baixa autoestima. É nesse contexto que deve se sobressair a sensibilidade do professor, pois se ele não notar os problemas de baixa autoestima de seus alunos, o mesmo pode se sentir não merecedor de afeto e estima, também. Para tanto, um aluno com baixa autoestima jamais terá um aprendizado satisfatório, pois entende que outros espaços, que não a escola, são bem mais atrativos e acolhedores. Nesse sentido, Maldonado (1994, p. 42) explica que:

[...] o professor pode reconhecer quando um processo de construção do conhecimento está sendo efetivo, quando o mesmo se permite sentir o processo. Assim como sente quando está havendo aprendizagem, se o clima em sala de aula é desagradável ou rico e construtivo.

O que a autora está a dizer é que, o professor, como sujeito mais experiente nas práticas sociais e nas próprias relações afetivas, deve buscar meios de orientar os alunos a experimentarem diferentes formas de afeto que tenham como proposição contribuir para que o aprendizado seja assegurado.

Na direção sinalizada por Maldonado (1994), convém destacar a importante contribuição de Woolfolk (2000) ao considerar que, na maioria das vezes, os professores se mostram incapazes de perceber e identificar a dinâmica do ser e se portar dos seres humanos, o que na prática os leva a fazer deduções que se mostram verdadeiros equívocos no que tange aos seus alunos, atribuindo na maioria das vezes as dificuldades de aprendizagem destes a fatores bem diferentes dos que realmente são.

É importante que o professor tenha clareza entre o que pode categorizar como indisciplina daquilo que são comportamentos emocionais fragilizados, pois esses são os maiores causadores do medo e insegurança dos alunos, o que implica instabilidade e dificuldade de aprendizagem. Woolfolk (2000) considera que, elas quase sempre estão presentes no espaço da sala de aula e que, o professor é o sujeito principal no sentido de diagnosticá-las e promover intervenções, de modo a assegurar o desenvolvimento sadio dos alunos em todos os aspectos. Sendo assim:

Os professores são a melhor fonte de ajuda para os alunos que enfrentam problemas emocionais ou interpessoais. Quando os alunos têm uma vida familiar caótica e imprevisível, eles precisam de uma estrutura firme e atenta na escola. Eles precisam de professores que estabeleçam limites claros, sejam consistentes, apliquem as regras firme, mas não punitivamente, respeitem os alunos e mostrem uma preocupação genuína com o seu bemestar. Como professor, você pode estar disponível para conversar sobre problemas pessoais sem exigir que seus alunos o façam (WOOLFOLK, 2000, p.47) 
Sobre as questões relacionadas ao processo ensino-aprendizagem, tanto Antunes (2006) como Maldonado (1994) e Woolfolk (2000) consideram a afetividade como de fundamental importância para 0 processo de aprendizagem e desenvolvimento dos sujeitos, o que os leva a considerar, dentro da perspectiva sóciointeracionsita, que o professor como mediador não apenas da relação de produção do conhecimento também estabelece limites e princípios que são necessários para o desenvolvimento das emoções/afetividade na sala de aula.

Rodrigues (1976), por sua vez, afirmou que, o ser humano, em especial a criança, aprende o que deseja, ou seja, o aprendizado é resultado de um processo motivacional que implica diretamente no seu desenvolvimento, dentro do qual a afetividade é tida como destaque, por entendermos que nem sempre os alunos procuram a escola para sanar sua necessidade do conhecimento. Muitas vezes tais alunos procuram esse espaço para ter aquilo que não têm nos espaços que frequentam, que é a questão do afeto, que acaba por impulsionar a aprendizagem. Assim,

\begin{abstract}
A aprendizagem escolar depende, basicamente, dos motivos intrínsecos: uma criança aprende melhor e mais depressa quando sente-se querida, está segura de si e é tratada como um ser singular (...). Se a tarefa escolar atender aos seus impulsos para a exploração e a descoberta, se o tédio e a monotonia forem banidos da escola, se o professor, além de falar, souber ouvir e se propiciar experiências diversas, a aprendizagem infantil será melhor, mais rápida e mais persistente. (RODRIGUES, 1976, p. 174).
\end{abstract}

No entendimento da autora, a criança não necessita apenas de conhecimentos científicos, ela necessita também de afeto, especialmente porque é a partir dos estímulos e incentivos que ela vai desenvolver suas potencialidades e habilidades. Dentro dessa lógica, não mais caberia um modelo de escola puramente técnica e burocrática, pois as necessidades dos alunos nos dias atuais voltam-se para aquilo que é dinâmico e interativo, daí a importância de se planejar aulas considerando as realidades diversas e necessidades de aprendizagem dos alunos.

Podemos então salientar que, a motivação do aluno na escola depende das relações que, são estabelecidas entre os sujeitos e situa-se naquilo que, o aluno quer aprender e como o professor trabalha as relações emocionais/afetivas no âmbito da escola. Assim, para se ter um panorama mais claro sobre as influências da afetividade nos processos de ensino e aprendizagem escolar é preciso considerar todas as dimensões afetivas, mais humanas do homem. Sobre os 
impactos diretos da afetividade no processo de aprendizagem, Rodrigues (1976, p. 179) explica que:

As situações de ensino agradáveis suscitam no aluno um desejo de repetir e renovar a aprendizagem. Quando, por infelicidade, o contrário acontece, o aluno tende a rejeitar não só a disciplina que não consegue aprender, mas também tudo quanto a ela se refira, inclusive o mestre e até a própria escola. Se a situação de aprendizagem é gratificante e agradável, o aprendizado tende a se dinamizar, a extrapolar-se para situações novas e similares e, por fim, a inspirar novas aprendizagens.

A partir do que apresenta a autora acima fica evidente que na maioria das vezes a causa do abandono/fracasso escolar, que interfere diretamente no desenvolvimento das potencialidades humanas, não é resultado das condições econômicas e políticas dos sujeitos, mas sim da questão afetiva, pois quando a criança não se sente acolhida e abraçada num determinado espaço, ela tende a procurar outros lugares para criar uma identificação e ressignificar aquilo ali para si. Rossini (2012, p. 09), ao considerar que: "as crianças que possuem uma boa relação afetiva são seguras, têm interesse pelo mundo que os cerca, compreendem melhor a realidade e apresentam melhor desenvolvimento intelectual".

De fato, as considerações da autora acima citada encontram ressonância nas nossas vivências em sala de aula, pois notamos, na carreira docente, que os alunos que possuem uma boa relação afetiva com seus professores, sempre apresentam um nível de desenvolvimento mais elevado, ao passo que os alunos arredios, apresentavam sérios problemas de aprendizagem.

Assim, podemos dizer que o homem e suas relações sociais são produtos históricos, e por esse mesmo viés a própria afetividade também é social e históricocultural, por se apresentar como inerente ao ser humano e ser produto do descobrimento e desenvolvimento da linguagem. Sob este prisma, depreende-se que:

[...] não é apenas uma das dimensões da pessoa; ela é também uma fase do desenvolvimento, a mais arcaica. O ser humano foi, logo que saiu da vida puramente orgânica, um ser afetivo. Da afetividade, diferenciou-se, lentamente, a vida racional. Portanto, no início da vida, afetividade e inteligência estão sincreticamente misturadas, com o predomínio da primeira. A sua diferenciação logo se inicia, mas a reciprocidade entre os dois desenvolvimentos se mantém de tal forma que as aquisições de cada uma repercutem sobre a outra permanentemente. (DANTAS, 1992, p.90).

A afetividade é a manifestação das diferentes formas de sentir, mas não apenas nisso, também nas formas comportamentais que são adotadas pelos sujeitos. Dessa forma, a interação sadia entre professores e alunos por meio de 
atitudes positivas faz com que o espaço da sala de aula torne-se um ambiente seguro e acolhedor para o aluno, que sente prazer em fazer parte dos momentos de interação e socialização.

Vygotsky (1998) e Wallon (1995;2010) se preocuparam em analisar e compreender, o desenvolvimento humano, a partir das capacidades mentais humanas e, nesse percurso, acabaram por evidenciar a relevância da afetividade para o processo de desenvolvimento das capacidades e potencialidades humanas.

Vigotsky (1998), ao desenvolver uma teoria do desenvolvimento humano, considerou que para que, este se efetive, faz-se necessário considerar a relação idiossincrática que existe entre o afeto e o intelecto. Para o desenvolvimento de uma teoria do desenvolvimento humano, ou pelo menos de algo que se aproximasse disso, o autor tensionou as categorias afeto e intelecto por meio de questionamentos que o levam a concluir que não existe um parâmetro, ou mesmo um estudo mais consolidado que aponte de maneira didática e sucinta como tais categorias se imbricam, mesmo estando no ser humano separadas.

É impossível para a nossa condição humana separar o cognitivo do afetivo psicológico, pois para ele tais categorias humanas se relacionam e têm pontos de partidas diferentes, mas não podem ser separadas, pois se corre o risco de reduzir as capacidades humanas às situações de treino e reprodução das situações socioculturais das quais fazem parte. De acordo com, Oliveira (1992, p. 76):

\footnotetext{
Vygotsky menciona, explicitamente, que um dos principais defeitos da psicologia tradicional é a separação entre os aspectos intelectuais, de um lado, e os volitivos e afetivos, de outro, propondo a consideração da unidade entre esses processos. Coloca que o pensamento tem sua origem na esfera da motivação, a qual inclui inclinações, necessidades, interesses, impulsos, afeto e emoção. Nesta esfera estaria a razão última do pensamento e, assim, uma compreensão completa do pensamento humano só é possível quando se compreende sua base afetivo-volitiva.
}

O desafio de desvendar o desenvolvimento do ser humano, levou Vigotsky (1998) a categorizar tal desenvolvimento em duas dimensões psicossociais que levam em consideração os níveis de tais processos: o nível de desenvolvimento real, que é tudo aquilo que a criança consegue fazer sozinha e o nível de desenvolvimento potencial, ou seja, o que a criança não consegue realizar sozinha, precisando da ajuda de um parceiro mais capacitado para realizar. Partindo de tais pressupostos, o papel do professor é mais complexo do que se pressupunha, em termos de dar aulas e encerrar as mesmas, pois perpassa por uma série de 
questões que são necessárias para que o desenvolvimento real e o desenvolvimento potencial subsidiem a chamada zona de desenvolvimento proximal.

A zona de desenvolvimento proximal é um importante instrumento nas mãos dos educadores, pois identifica não somente o desenvolvimento real, como também o desenvolvimento potencial. O docente, ao saber que a criança já é capaz de fazer sozinha, atua na segunda situação. "Assim a zona de desenvolvimento proximal capacita-nos a propor uma nova fórmula, a que o 'bom aprendizado' é somente aquele que se adianta ao desenvolvimento" (VIGOTSKY, 1998, p. 117)

A teoria de Henri Wallon se centraliza na afetividade, pois uma das grandes contribuições de sua teoria para o desenvolvimento humano é a emoção. Logo, considera as emoções essenciais para a sobrevivência humana, uma vez que a emoção é colocada em evidência desde os primeiros anos de vida de uma pessoa. Para Wallon (1995), o desenvolvimento humano, com base em pressupostos afetivos, passa por uma transição básica que envolve o estado orgânico e a etapa cognitiva. Explicando os princípios de tal teoria do desenvolvimento humano Dantas (1992, p. 85) diz que:

Para Wallon, é através da atividade emocional que se realiza a transição entre o estado orgânico do ser e a sua etapa cognitiva racional, que só pode ser atingida através da mediação cultural, isto é, social. A consciência afetiva é a forma pela qual o psiquismo emerge da vida orgânica: corresponde à sua primeira manifestação. Pelo vínculo imediato que se instaura com o ambiente social, ela garante o acesso ao universo simbólico da cultura, elaborado e acumulado pelos homens ao longo de sua história. Dessa forma é ela que permitirá a tomada de posse dos instrumentos com os quais trabalha a atividade cognitiva. Neste sentido, ela lhe dá origem.

A dimensão afetiva é de fundamental importância para Wallon, seja ela do ponto de vista da construção da pessoa ou do ponto de vista do conhecimento, sendo marcante para o desenvolvimento da espécie humana, que se manifesta a partir do nascimento e se estende ao longo dos anos de vida. Assim, para o autor a afetividade tem um papel imprescindível no processo de desenvolvimento da personalidade humana.

Em linhas gerais temos evidenciado que a afetividade tanto em Vigotsky como também em Wallon é de fundamental importância, pois integra o aspecto sócio-histórico-cultural na formação do homem, de sua personalidade, tendo assim, uma abordagem de desenvolvimento com cada um à sua maneira, mostrando que as manifestações emocionais têm um caráter orgânico influente. 


\section{Vivências afetivas no ambiente escolar: a relação professor-aluno}

Quando mencionamos o termo vivências afetivas no ambiente escolar, estamos nos referindo a todo e qualquer envolvimento que tem como protagonista os sujeitos presentes na escola. Ou seja, em decorrência do tempo estimado para o desenvolvimento das aulas, que se configura como tempo de permanência na escola, cria-se uma vida alternativa a que se tem normalmente, pois a instituição escolar tem uma rotina que se difere da vida fora dela.

Nesse sentido, no universo chamado escola, são experimentadas por professores e alunos diferentes manifestações da afetividade, que acabam por nos possibilitar chamar de vivências, já que se tratam de experiências individuais e coletivas que irão marcar profundamente tanto o aluno (sujeito aprendente) quanto o professor (sujeito experiente das práticas sociais).

Sendo assim, no espaço da sala de aula, o que temos é um encontro de sujeitos do conhecimento, mas com suas particularidades. Nesse caso, trata-se da subjetividade (vista como aquilo que é particular, singular e que caracteriza alguém) onde se percebem enquanto "eu", que se difere daquele com quem convivo, o "outro".

Kieckhoefel (2011) considera que desde muito cedo estamos envolvidos em situações diversas e ambíguas, numa espécie de troca reciproca com nossos pares, seja pela concordância ou pelo contrário, haja vista que nos apresentamos para os "outros como seres ora dotados de saberes, ora em busca de saberes. Essa ambiguidade que nos cerca e nos acompanha deixa evidente o quanto somos diferentes uns dos outros" (KIECKHOEFEL, 2011, p. 2536).

Nesse sentido, somos seres com particularidades e saberes que nos diferenciam um dos outros, sendo assim identificados como únicos (até mesmo em termo genéticos, pois cada pessoa possuí uma digital, uma carga genética que se equipara, mas que nos diferencia um dos outros) por nossas atitudes $e$ comportamentos (que formam nossas identidades). Porém, essas diferenças é que são a possibilidade de completarmos uns aos outros, para assim, ser uma só totalidade, nos configurando como seres completos e que contribuí para a formação de outros seres completos (KIECKHOEFEL, 2011).

Pensando em trazer uma reflexão crítica sobre a questão das diferenças, mas pautada nos princípios da afetividade, é que Ranghetti (2002, p.87-89) entendeu que vivenciar no espaço escolar as diferenças "é viver a própria 
afetividade sendo presença, acolhendo o outro para um renascer com-junto em meio à diversidade das singularidades". Note-se que a autora, por meio do hífen, cria um neologismo para representar não um "conjunto" na ideia de unidades que o forma, mas a ideia de "com", numa perspectiva de integração e trocas, e juntos no sentido de nos influenciarmos mutuamente.

As considerações de Ranhgetti (2002) nos levam a perceber que a afetividade se constrói "na" e "com" as diferenças, não numa imediata concepção de aceitação, mas de respeito e valorização do outro como ele o é. Nesse sentido, Kieckhoefel (2011) considera que a todos os instantes estamos experienciando situações afetivas em nossa vida, em maior ou menor grau. Por isso, a necessidade de construir uma relação harmoniosa e pautada no respeito de professores e alunos.

A nosso ver o sujeito mais experiente tanto nas práticas sociais como emocionais, que é o de "perceber o outro, acolhê-lo para, juntos, renascer, reconstruir, ser" (RANHGETTI, 2002, p. 89). Indo mais longe, a autora menciona que o processo ensino-aprendizagem só ganha sentido a partir do momento que se estabelece um "acordo" entre professores e alunos. Tal acordo funciona como uma espécie de troca e mediação do conhecimento. Sendo assim, Kieckhoefel (2011, p. 2537) considera que: “Esse 'acordo' é condição fundamental e imprescindível para que o saber seja proveitosamente trabalhado".

A partir da ótica vygotskiana, entendemos, a mediação como produto de uma relação entre dois sujeitos com um objeto do conhecimento. Esclarecendo, a lógica desse pensamento, Smolka e Góes (1995, p.9) salientam que: "Isto significa dizer que é através de outros que o sujeito estabelece relações com objetos de conhecimento, ou seja, que a elaboração cognitiva se funda na relação com o outro". Nessa relação com o outro, o fator afetivo é determinante, pois se os sujeitos não se identificam, o processo de aprendizagem pode ser totalmente comprometido.

Não tem como pensar situações de ensino e aprendizagem sem levar em consideração o fator afetivo, pois, como já se disse neste trabalho, tal condição é natural do ser humano por sua condição histórica, cultural e social. Dessa forma, toda situação de aprendizagem envolve afetividade, seja ela positiva ou negativa. $A$ seu modo particular Davis e Oliveira (1994, p. 83-84) registram que:

As emoções estão presentes quando se busca conhecer, quando se estabelece relações com objetos físicos, concepções de outros indivíduos. Afeto e cognição constituem aspectos inseparáveis, presentes em qualquer atividade, embora em proporções variáveis. A afetividade e a inteligência se estruturam nas ações e pelas ações dos indivíduos. O afeto pode, assim, 
ser entendido como uma energia necessária para que a estrutura cognitiva passe a operar. E mais: ele influencia a velocidade com que se constrói o conhecimento, pois quando as pessoas se sentem seguras, aprendem com mais facilidade.

Diante do exposto, consideramos que, o professor estar colocado em uma encruzilhada entre ser afetivo ou não, de modo que se este profissional compreende e valoriza a presença da afetividade, inclusive criando situações e espaços para que ela se manifeste nas relações de ensino e aprendizagem, que podem fazer com ele se torne inesquecível para seus alunos, seja pelo exemplo de pessoa que é, seja pelo conhecimento que compartilha em suas aulas. Do contrário, o professor fica marcado na memória dos alunos, mas a partir de uma imagem negativa e causadora de medo e receio, o que consiste em situação constante de fracasso escolar.

Sobre a vivência afetiva na educação, especialmente no que tange a relação que se estabelece entre professores e alunos, Ranghetti (2002, p. 87), considera que:

Sentir e viver a afetividade na educação, [...], suscita que nosso eu adentre
a sala de aula, inteiro, para desvelar, descobrir e sentir as manifestações
presentes nas interações, relações e reações que os sujeitos
estabelecem/manifestam na ação de educar. É ampliar o olhar e a escuta
na tentativa de captar da expressão/comunicação destes seres o revelar do
seu eu, sua inquietude, dificuldade e possibilidade que expressa na ação de
aprender e de ensinar. Uma ação consciente, partilhada e envolvente, visto
que os sujeitos devem se apresentar inteiros para que esta ação seja
significativa e com sentido à sua existência.

Considerando o exposto, podemos considerar que as situações de ensino e aprendizagem são permeadas de sentidos e significados linguísticos e afetivos, o que implica dizer que, a relação professor-aluno, que é decorrente das situações de ensino-aprendizagem, envolve trocas de saberes e de sentimentos/sensações, o que a torna flexível e móvel, por ser transformada e ao mesmo tempo transformar os sujeitos que protagonizam tais situações. Assim, as manifestações, especialmente do aprender e dos processos afetivos, são atributos constantes e de grande relevância na vida humana, pois tais manifestações implicam diretamente no êxito ou o fracasso do aluno e também do professor.

$\mathrm{Na}$ relação professor-aluno as situações afetivas, ou mesmo o afeto, são um componente indispensável e de grande valor, pois, possibilitam e potencializam, o desenvolvimento da criança de forma saudável, além de dispor para o professor a oportunidade de estabelecer uma relação que realmente possa ser útil para, o seu 
crescimento pessoal e de seu aluno, e que abrangerá todos os aspectos de sua vida, seja o pessoal, o social, o profissional.

O ato de aprender, ou a prática educativa, é um momento de construção como destacado anteriormente, construção não apenas do conhecimento, mas da identidade dos sujeitos envolvidos em situações de ensino e aprendizagem. Dessa forma, o professor necessitar ter consciência de que não apenas ensina, mas que também aprende, à medida que não é o dono do conhecimento e nem poderá determinar o ritmo e a forma de aprendizagem de seus alunos.

Almeida (2004, p. 126) considera que "[...] o professor precisa criar condições afetivas para o aluno atingir a plena utilização do funcionamento cognitivo e vice-versa". Dessa forma, o professor é visto como um sujeito de grande relevância no processo de aprendizagem, especialmente por ser o motivador, ou seja, aquele que deixa transparecer um prazer em mediar o conhecimento (em tornar possível o aprendizado), tornando a relação do aluno com o objeto do conhecimento a menos dolorosa possível e, consequentemente, mais prazerosa.

Diante do exposto, entendemos que, cabe ao professor, não ao sujeito em si, mas principalmente ao profissional, canalizar a afetividade para produzir conhecimento, o que na prática se configura como"[...] reconhecer o clima afetivo e aproveitá-lo na rotina diária da sala de aula para provocar interesse ao aluno" (ALMEIDA, 2004, p.126).

Considerando a escola como um espaço privilegiado de socialização, que nas relações estabelecidas entre professor e alunos, o professor deve se apresentar como um incentivador, ou mesmo, aquele sujeito que motiva os alunos a se lançarem ao desafio da construção do conhecimento a partir de diferentes situações de aprendizagem, pois quando o faz dessa forma, identifica em que momentos deve intervir para assegurar a aprendizagem eficaz de seus pupilos. Nesse sentido, Bueno (apud KIECKHOEFEL, 2011, p. 2538) afirma:

É muito melhor aprender e ensinar quando existe afeto envolvido. Afeto não é apenas beijinhos, palavras melosas. Afeto é afetar. É o compromisso de transformar o outro. [...] $O$ afeto está na preparação da aula. Nas escolhas do professor. Na voz, no toque, nos pequenos gestos. No silêncio, na forma como esse avalia. Aprendi que de nada vale estar em uma superescola, com um supermaterial, num superespaço, numa superlinha pedagógica se não há seres capazes de afetar e dispostos a serem afetados pelos outros! Afeto é o que fica. 
De nada importa os recursos matérias, a qualificação profissional, se estas não estiverem conectados a um trabalho em que, as pessoas se permitam ser tocadas pelo outro (não em termos físicos propriamente dito, mas em termos sensitivos, afetivos), ou melhor, afetadas mutuamente, pois na maioria das vezes os próprios conteúdos e saberes se tornam obsoletos, mas o afeto fica registrado na memória humana.

A aprendizagem é movimento. Da mesma forma, a relação professor-aluno deve estar em movimento, pois as pessoas não são, mas estão sendo e podem ser de maneira intensa, transformadas. Por isso, o professor não deve silenciar as práticas afetivas em seu trabalho pedagógico, mas deve planejar aulas e intervenções didático-pedagógicas, em que, a afetividade seja, a mola propulsora do ato de conhecer e descobrir. Neste sentido, Vasconcellos (2009, p. 64) explica que:

\begin{abstract}
A vida afetiva e a vida cognitiva são inseparáveis, embora distintas. Elas são inseparáveis porque qualquer troca com o meio supõe simultaneamente uma estruturação e uma valorização [...]. É por este motivo que é impossível pensar, mesmo em matemáticas puras, sem experimentar alguns sentimentos, e que, inversamente, não existem fenômenos afetivos sem um mínimo de compreensão ou de discriminação.
\end{abstract}

Essas configurações relacionais é que vão atribuir significado ao trabalho docente e à própria construção do conhecimento por parte do aluno, pois as situações de aprendizagem configuram como momentos de intensa e fluída troca entre professores e alunos, pois tanto um como o outro, ensina e aprende na mesma intensidade, tendo como variação, em alguns casos apenas, as questões emocionais e afetivas. Assim, a relação do professor com o aluno na sala de aula deve ser baseada no diálogo e respeito ao outro (suas crenças, culturas, ideias e comportamentos). É preciso falar, enquanto docente, mas se faz necessário, também, ouvir e compreender os sujeitos que falam e de onde (em termos afetivos).

Por isso, é de suma importância que o professor conheça a realidade e as experiências da própria existência de seus educandos, pois isso Ihe permitirá planejar situações de aprendizagem em que todos se sintam importantes e valorizados, o que é tido como base fundamental para a motivação dos alunos para descobrir e aprender o novo.

Consideramos que, para educar, o professor necessita estabelecer com seus alunos, uma relação bem mais profunda do que a ligação técnica do seu compromisso de ensinar, já que, não é suficiente, o desenvolvimento da tarefa de tornar possível o aprendizado dos alunos por meio de métodos e técnicas, É preciso 
que, se estabeleça uma relação de sujeitos que se integram, se misturam e se completam, pois o aluno quer aprender e o professor quer ensinar, mas para que o ensino-aprendizagem aconteça é preciso criar um ambiente favorável em que a afetividade assuma papel de destaque.

\section{CONSIDERAÇÕES FINAIS}

É notório o desafio a que estamos sendo chamados a responder nos dias atuais enquanto professores, enquanto membros da instituição escolar. A escola precisa ser na atualidade bem mais que um espaço em que os sujeitos vão para "receber" conhecimento. Ela necessita se apresentar como um espaço de encontro entre pessoas diferentes, mas que buscam objetivos que ao mesmo tempo passam pelo imaginário coletivo, mas se configuram como individual.

A escola necessita assumir de fato o seu papel de socializadora do conhecimento e trocas sociais entre sujeitos. Nesse sentido, a escola não deve ser para o aluno apenas um espaço formal para o qual ele vai em busca de construir conhecimento. Isso perpassa por um processo de repensar a instituição escolar e seus profissionais como um espaço onde os sujeitos tenham assegurada a possibilidade de desenvolver suas potencialidades por meio de práticas pedagógicas que os reconheçam como sujeitos de direito, que necessitam bem mais que conhecimento científico no âmbito da escola, mas de abrigo e atendimento às suas necessidades.

A escola precisa, de maneira organizada, desenvolver nos alunos um espírito coletivo, que ajude a conceber o processo ensino-aprendizagem como uma troca de saberes e relações afetivas. A afetividade não pode deixar de ser problematizada no espaço da sala de aula, pois a aprendizagem se relaciona diretamente com tal processo. Pois, como demonstrou esse estudo por meio de seus referenciais teóricos, a afetividade é necessária na formação de pessoas felizes, éticas, seguras e capazes de conviver com o mundo que as cerca. Assim, no ambiente escolar, a afetividade vai além de dar carinho e atenção. É aproximar-se do aluno, saber ouvi-lo, valorizá-lo e acreditar nele.

Vale ressaltar que os objetivos propostos para este artigo foram alcançados, pois foi possível perceber a importância que um trabalho pedagógico escolar com base na afetividade desempenha no desenvolvimento integral dos sujeitos. A afetividade com base nos referenciais teóricos que apresentamos ao longo do texto 
contribui de forma positiva ou negativa, cabendo ao professor fazer a mediação ao longo desse processo vivenciado na rotina escolar pelo aluno.

\section{REFERÊNCIAS}

ALMEIDA, L. R. Ser Professor: Um diálogo com Henri Wallon. In: MAHONEY, A. A., ALMEIDA, L. R. (Orgs). A constituição da pessoa na proposta de Henry Wallon. São Paulo, Loyola, 2004.

ANTUNES, Celso. A afetividade na escola: educando com firmeza. Londrina: Maxprint, 2006.194p.

ARROYO, Miguel. Oficio de Mestre. Imagens e auto-imagens. Petrópolis, RJ: Brasil, 2001.

DANTAS, $\mathrm{H}$. Afetividade e a construção do sujeito na psicogenética de Wallon. In: DANTAS, H.; DE LA TAILLE, Y. \& OLIVEIRA, M. K. Piaget, Vygotsky, Wallon: teorias psicogenéticas em discussão. São Paulo: Summus, 1992.

DAVIS, Cláudia; OLIVEIRA, Zilma de M. Ramos. Psicologia na educação. São Paulo: Cortez, 1994.

KIECKHOEFEL, Josiane Cardozo. As relações afetivas entre professor e aluno. $X$ Congresso Nacional de Educação - EDUCERE; I Seminário Internacional de Representações Sociais, Subjetividades e Educação - SIRSSE; Pontifícia Universidade Católica do Paraná; Curitiba, 2011.

MALDONADO, Maria Tereza. Aprendizagem e afetividade. Revista de Educação AEC, v.23, n.91, p.37-44, 1994.

OLIVEIRA, M. K. O problema da afetividade em Vygotsky. In: DANTAS, H.; DE LA TAILLE, Y. \& OLIVEIRA, M. K. Piaget, Vygotsky, Wallon: teorias psicogenéticas em discussão. São Paulo: Summus, 1992, p. 75-84.

RANGHETTI, Diva Spezia. Afetividade. In: FAZENDA, Ivani. Dicionário em Construção: Interdisciplinaridade. 2.ed. São Paulo: Cortez, 2002. p.87-89.

RODRIGUES, Marlene. Psicologia educacional: uma crônica do desenvolvimento humano. São Paulo: Mc Graw-Hill do Brasil, 1976. p. 305.

ROSSINI, Maria Augusta Sanches. Pedagogia Afetiva - 13.ed. Petrópolis, Rio de Janeiro: Vozes, 2012.

SMOLKA, A. L. B.; GÓES, M. C. (Orgs). A linguagem e o outro no espaço escolar: Vygotsky e a construção do conhecimento. São Paulo: Editora Papirus, 1995.

VYGOTSKY, L. S. A formação social da mente: o desenvolvimento dos processos psicológicos superiores. 6.ed. São Paulo: Martins Fontes, 1998 
WALLON, Henri. A evolução psicológica da criança. Henri Wallon; com introdução de Émile Jalley. 2.ed. São Paulo: Martins Fontes, 2010.

Psicologia e educação da infância. Lisboa: Estampa, 1995.

WOOLFOLK, Anita E. Psicologia da Educação. $7^{a}$ ed. Porto Alegre: ArtMed,2000. 